maceuticals but has not yet done so, although its federal registry notice indicated it could include epinephrine, antihypertensives and all diabetes medications (www.gpo.gov/fdsys/pkg/FR -2012-02-28/pdf/2012-4597.pdf).

To skeptics, that's like letting passengers fly the plane with flight attendants looking over their shoulder and the pilot nowhere in sight.

"Chilling and a little scary," Dr. Bobby Quentin Lanier, executive director of the American College of Allergy, Asthma and Immunology, told the FDA's hearing on the matter. "Now let me say we're not Luddites. We know change is inevitable. But we want the change to be better. And what we envision, with hearing some of the issues today, is chaos."

Over the decades, various drugs have migrated to nonprescription status and become more widely used, from fluoride to antifungals. Self-treatment advocates say many lives have been saved by making smoking-cessation aids available over the counter. They also believe treatment would reach many of the estimated seven million Americans with undiagnosed diabetes if easier pathways to drugs were established.

As envisioned by the FDA, information kiosks at pharmacies and userfriendly computer algorithms online would walk people through questionnaires helping them determine if they need a drug or should visit a doctor. Pharmacists are key players - the only health care professionals patients would need to consult in most cases. In some instances, an initial doctor's visit would be required, but not follow-ups to remain on a medication.

Robb McGory, pharmacy director at the Indian River Medical Center in Vero Beach, Florida, welcomes the initiative even if there are many unresolved ques-

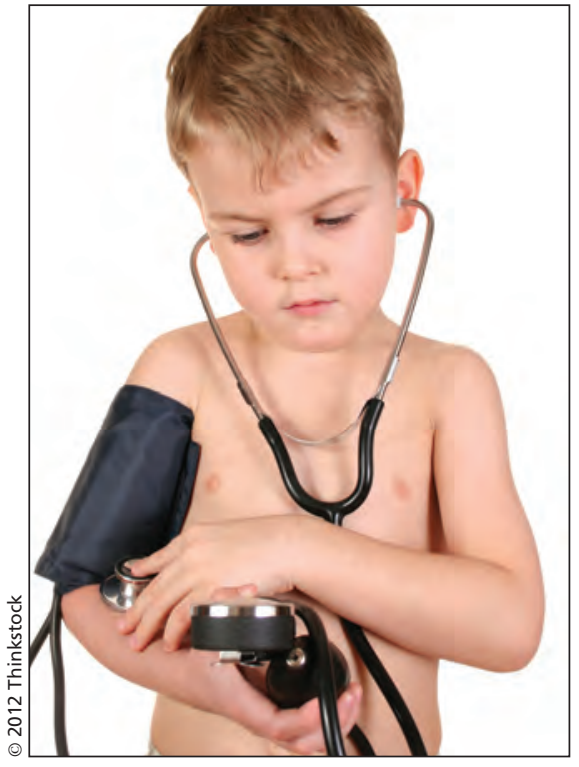

Self-diagnosis is a risky foundation on which to base the use of pharmaceuticals, critics say of the United States Food and Drug Administration's proposal to create a new category of drugs for diabetes, asthma, migraines, hypertension and other diseases.

tions about how it might unfold. "Years ago, patients started going to nursepractitioners who had diagnostic capabilities," he says. "The pharmacist is stepping into that role. We are going through a time of change, legally and professionally. We are expected to do more than fill a prescription."

Among the questions is who pays for the drugs. Both the private health insurance industry and government coverage for the elderly and the poor typically pay for prescription drugs, with other meds coming out of pocket. The new category of drugs is likely to fall into the latter group, which makes it appealing to politicians and health administrators. Cutting doctors out of some diagnoses may save the health system considerable money, shifting more costs to patients.
Dr. Richard Milsten, a urologist and member of the Indian River Medical Center Foundation board, says patients will likely diagnose themselves based solely on symptoms, without regard to other nuances that physicians utilize, such as physical appearance and examination findings.

"Patients will be right many times in their diagnosis, but I think there will be a significant error rate as well," Milsten says. "When you hear hoof beats, it is usually a horse; but every now and then it will be a raging bull. I think some patients are going to get trampled by their own misdiagnosis resulting in a delay in accurate diagnosis. This will result in prolonged suffering or worse."

With more than 30 million people expected to gain health insurance as a result of President Barack Obama's health reforms, moving some into selfdiagnosis and self-medication mode would not only reduce costs and strain on primary care facilities but, in theory, free doctors from some of the burdens of routine care and give them more time for complex cases.

But the American Medical Association isn't keen on any plan that sidelines doctors, suggesting that personalized medical information from a computer is not the same as personal care from a physician. The risks of dispensing drugs without a prescription can include a failure to detect a disease's progression or the need for changes in dosage.

Others have countered that there are dangers in the status quo which point to the need to make drugs more accessible, including the tendency for people with certain conditions, such as chronic diseases, to leave therapy at alarmingly high rates. - Cal Woodward, Washington DC

CMAJ 2012. DOI:10.1503/cmaj.109-4220

\title{
Infoway to become more responsive to needs, CEO vows
}

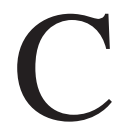
anada Health Infoway must rapidly reboot, and do so in substantial fashion, if it's to justify public outlays beyond the billions already spent on developing a national electronic health infrastructure, according to the crown corporation's CEO.
After years of defending a strategy favouring massive centralized data systems over meaningful use of electronic health data by physicians and patients, Richard Alvarez, Infoway's top mandarin, told an audience in Vancouver, British Columbia, on May 29 that the agency must reprioritize its activities - Canada's existing approach has left it lagging dismally behind international counterparts such as Australia and New Zealand in achieving health improvements through electronic technologies. 


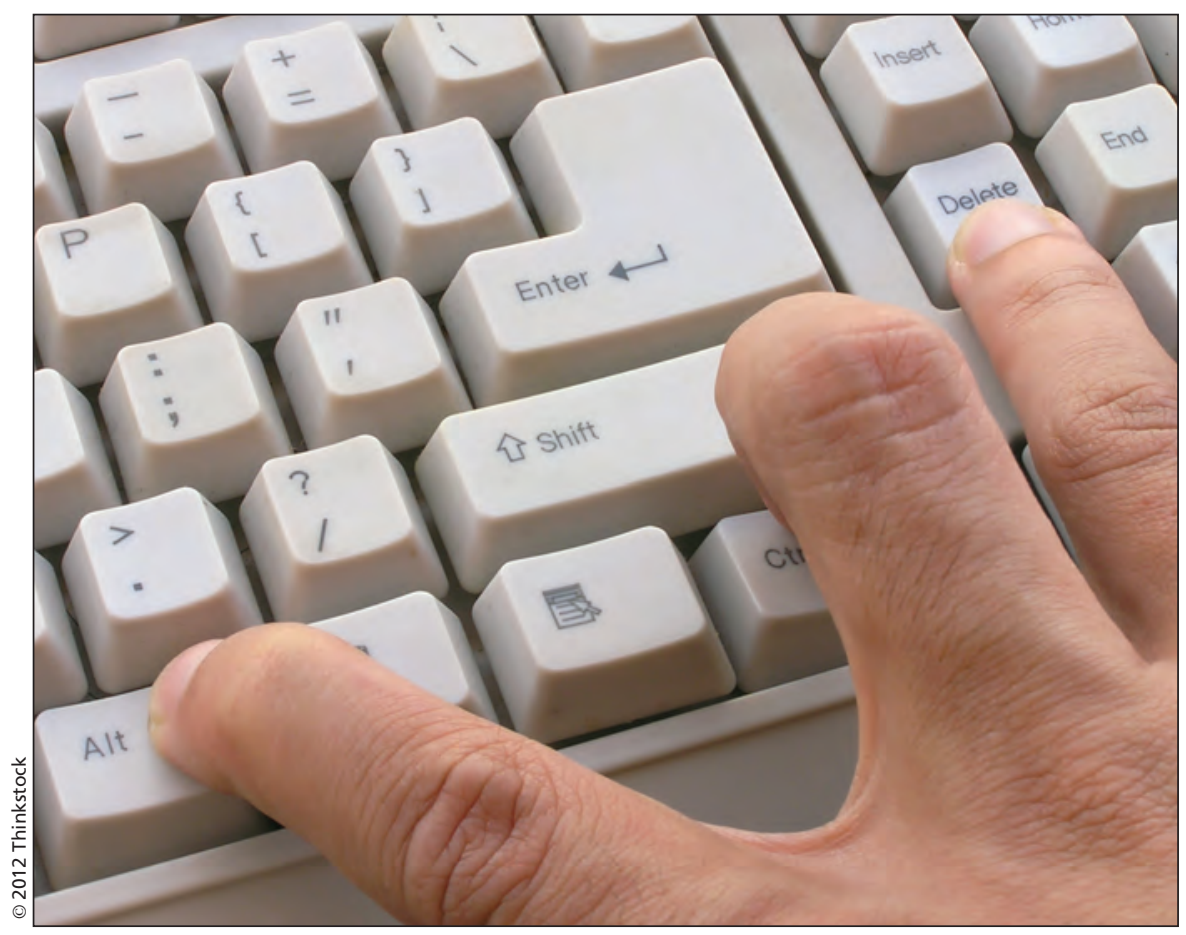

Canada Health Infoway has long been assailed for its e-health strategy and a long list of critics has long contended that its approach needed to be refocused. CEO Richard Alvarez says that reset is coming.

The deficiency is particularly acute with regard to physician use of electronic medical records, Alvarez said. "We've got to get the numbers up."

Infoway's top priority in the future must be to develop "consumer health systems" that permit "patient monitoring at home," Alvarez told delegates to e-Health 2012: Innovating Health eCare. There is "evidence from around the world" that consumers are demanding such systems, he added.

Alvarez laid out the proposed change as a necessary condition to receiving new funding from the federal government. The agency, created in 2001, has already received roughly $\$ 2.1$ billion, though funding is scheduled to expire in 2015.

Should it receive more money, Alvarez said, the agency will pursue the development of systems to provide an "enhanced patient experience" centred on e-scheduling of appointments, e-prescribing and e-visits (i.e., electronic patient-client encounters).

"I can do this in every other part of my life, why not health care?" he asked.

Infoway would also "support new models of care" that promote patient safety through such means as greater connect patients, Alvarez admitted "it is the will of the people to move in this direction" and screened a video of a ship captain ordering a lighthouse to clear his path, but Infoway has yet to commit more than a sliver of its budget in such a direction.

Infoway has long been assailed for its e-health strategy and many critics have contended that its approach needs refocussing (www.cmaj.ca/lookup/doi /10.1503/cmaj.109-3744). The litany of woes include an external performance audit commissioned by the agency that indicated it missed its program targets by a wide margin (www.cmaj.ca/lookup /doi/10.1503/cmaj.109-3860) and assertions from the Auditor-General of Canada that implementation of the national e-health strategy has been "haphazard" (www.cmaj.ca/lookup/doi /10.1503/cmaj.109-3242). Progress has been so dismal and outlays so wasted that some observers have urged that an independent national "watchdog" be appointed to assess and oversee federal e-health efforts (www.cmaj.ca/lookup /doi/10.1503/cmaj.109-3783).

But Alvarez told the Vancouver audience the failures have been a function of complexity. "We're not there yet because it's hard," he said. "We can take solace in that."

Alvarez also said physicians have lacked "motivation" in adopting electronic medical records, and that there "doesn't seem to be a push from patient safety advocates."

There has been progress, though, in telehealth, drug information systems and diagnostic imaging, Alvarez said, asserting that Infoway investments have generated more than $\$ 6.2$ billion in benefits since 2007.

Alvarez said Infoway consulted 500 people in crafting its plan to convince the federal government to extend funding. Infoway has long estimated that implementing its blueprint, issued in 2006 , will cost at least $\$ 10$ billion - or an additional $\$ 8$ billion. A revised blueprint, once promised for 2010, remains incomplete, Alvarez told CMAJ. "When it is ready, we will send it to you." - Paul Christopher Webster, Vancouver, BC

CMAJ 2012. DOI:10.1503/cmaj.109-4219 